\title{
Pseudoamniotic band syndrome after bipolar cord coagulation in monochorionic twins complicated by twin-to-twin transfusion syndrome
}

\author{
Anubhuti Rana, Vatsla Dadhwal, Peyyala Shainy, K Aparna Sharma
}

Obstetrics and Gynecology, All India Institute of Medical Sciences, New Delhi, Delhi, India

\section{Correspondence to Dr K Aparna Sharma; kaparnasharma@gmail.com}

Accepted 28 June 2021

\section{DESCRIPTION}

A 28-year-old primigravida presented at 24 weeks 3 days of gestation with spontaneous monochorionic diamniotic twin pregnancy and complaints of reduced fetal movements. Ultrasound (USG) examination revealed Quintero stage IV twin-to-twin transfusion syndrome (TTTS). After counselling, the patient successfully underwent selective fetal reduction of the recipient hydropic twin by bipolar cord coagulation (BCC) at 24 weeks 6 days of gestation. There were no intraprocedural or immediate postprocedural complications. Follow-up USG examinations did not show any evidence of chorioamniotic separation (CAS). However, at 29 weeks gestation (postselective fetal reduction day 32 ), she presented with preterm premature rupture of membranes. Antibiotics and steroid cover were started, after which she underwent lower-segment caesarean section at 29 weeks and 2 days of gestation in view of fetal bradycardia. A male baby weighing $980 \mathrm{~g}$ with Apgar scores of 4 and 6 at 1 and $5 \mathrm{~min}$, respectively, was delivered.

Incidentally, a constriction band was noticed above the right ankle with gross oedema and cyanosis of the right foot; however, no necrosis was noted (figure 1A,B). After plastic surgery and paediatric surgery consultations, the constricting band was divided, followed by local mupirocin application at the constriction site and magnesium sulfate application over the edematous foot (figure 1C,D). At discharge, the oedema had subsided and the constriction site had re-epithelialised completely with intact sensory as well

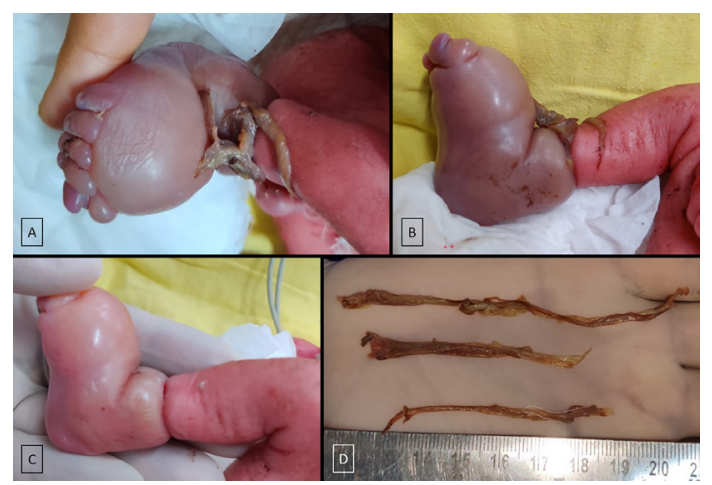

Figure 1 (A, B) depict the constriction band above the right ankle with gross oedema and cyanosis of the right foot. No necrosis is noted. (C) shows the immediate postsurgical release appearance of the right foot while (D) shows the divided constricting bands.

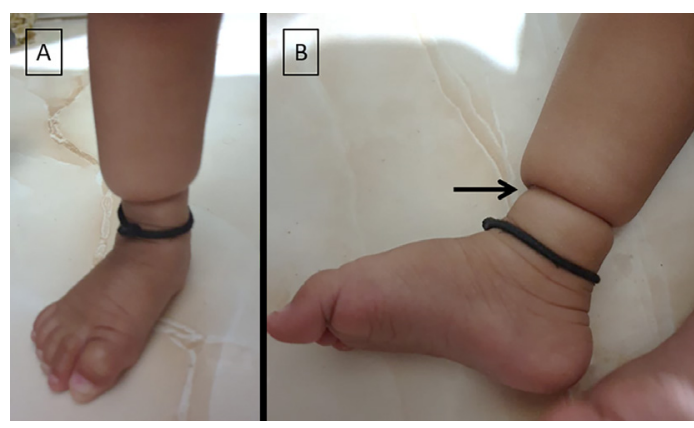

Figure 2 (A, B) show a concentric contracture (black arrow in B) at the site of initial constriction with a normal appearing right foot.

as motor functions of the right foot. At 1-year follow-up, the right foot was normal both functionally and morphologically; however, a concentric contracture had developed at the site of initial constriction (figure 2).

Pseudoamniotic band syndrome (PABS) is an unusual iatrogenic problem, secondary to in utero fetal interventions with clinical, sonographic and histologic features similar to amniotic band syndrome. It is characterised by entanglement of fetal parts or umbilical cord in a sheet of detached amniotic membrane potentially resulting in serious consequences such as limb constriction/ amputation, cord accidents or even intrauterine fetal death. ${ }^{1}$ It is commonly seen following fetoscopic laser photocoagulation for TTTS with an incidence of $1.8 \%-3.3 \%$, but can also occur following BCC, septostomy and amnioreduction. ${ }^{1}$ Possible explanations include CAS at the entry site during invasive interventions with subsequent formation of fibrous bands from the surface of chorion, and unintended septostomy during the procedure. ${ }^{2}$ A possible preventive measure could be avoiding perforation of the inter-amniotic membrane while inserting the fetoscope.

On follow-up, USG post in utero fetal interventions, a floating membrane possibly indicating septostomy or CAS should raise a reasonable degree of suspicion. Targeted, serial threedimensional USG of the fetal limbs and umbilical cord should be done weekly as complications can develop over 4-6 weeks. An intensive fetal surveillance can lead to prompt diagnosis, counselling and treatment. ${ }^{3}$ After diagnosis of PABS is confirmed, weekly follow-up with colour Doppler should be performed to detect impaired blood flow in the distal part of the affected extremity. 
Once compromise in vascularisation is detected, possible antenatal management options include fetoscopic release of the pseudoamniotic band to save the fetal limb from amputation. ${ }^{1}$

\section{Learning points}

- Pseudoamniotic band syndrome is similar to amniotic band syndrome and can lead to devastating consequences such as limb amputations or intrauterine death; however, this term is used when it occurs secondary to invasive in utero interventions.

- A high degree of suspicion is necessary for prenatal diagnosis in the postoperative period and follow-up with serial ultrasound is imperative for early detection.

- Fetal limb can be saved from serious complications such as amputation by in utero fetoscopic release of the pseudoamniotic band, if impaired blood flow is detected on follow-up ultrasound.

Contributors AR has participated sufficiently in the conception of the idea, development of the intellectual content, design, writing and final approval of the manuscript. VD has participated sufficiently in the conception of the idea, development of the intellectual content, design, writing and final approval of the manuscript. PS has participated sufficiently in the conception of the idea, development of the intellectual content, design, writing and final approval of the manuscript. KAS has participated sufficiently in the conception of the idea, development of the intellectual content, design, writing and final approval of the manuscript.

Funding The authors have not declared a specific grant for this research from any funding agency in the public, commercial or not-for-profit sectors.

Competing interests None declared.

Patient consent for publication Obtained.

Provenance and peer review Not commissioned; externally peer reviewed.

\section{REFERENCES}

1 Nassr AA, King A, Espinoza J, et al. Successful release of pseudoamniotic bands after laser photocoagulation for twin-twin transfusion syndrome: utility of partial carbon dioxide insufflation of uterus. Ultrasound Obstet Gynecol 2020;55:134-5.

2 Lafitte AS, Verspyck E, Jeanne Pasquier C, et al. Pseudoamniotic band syndrome after Fetoscopic laser ablation of placental anastomoses for twin-twin transfusion syndrome: two case reports and systematic review. J Ultrasound Med 2017;36:2373-7.

3 Rodrigues A, Araújo C, Carvalho R, et al. Limb constriction secondary to pseudoamniotic band syndrome after selective fetoscopic laser surgery: report of a case with a favorable outcome. Fetal Diagn Ther 2012;32:288-91.

Copyright 2021 BMJ Publishing Group. All rights reserved. For permission to reuse any of this content visit

https://www.bmj.com/company/products-services/rights-and-licensing/permissions/

BMJ Case Report Fellows may re-use this article for personal use and teaching without any further permission.

Become a Fellow of BMJ Case Reports today and you can:

- Submit as many cases as you like

- Enjoy fast sympathetic peer review and rapid publication of accepted articles

- Access all the published articles

Re-use any of the published material for personal use and teaching without further permission

Customer Service

If you have any further queries about your subscription, please contact our customer services team on +44 (0) 2071111105 or via email at support@bmj.com.

Visit casereports.bmj.com for more articles like this and to become a Fellow 